\title{
Dariusz Cegielski
}

Trans Polonia S.A., Poland

\section{DIAGNOSIS AND GROWTH PERSPECTIVES OF THE CHEMICAL LIQUID MATERIALS TRANSPORTATION MARKET IN THE EU}

\begin{abstract}
The paper presents the specifics of the global liquid chemical materials market. The increasing role of China is very significant in the prediction of the growth of the market. The changes of the structure of the primary market naturally lead to the changes in the transportation market of chemical liquid materials. The road transport still holds its significance, especially in the European Union, but intermodal transport also increases. The changes are affected by the legal regulations and the transport policy of the European Union, which might disturb the picture of the market within the next 10 years.
\end{abstract}

Keywords: road transport, liquid materials, european market

JEL: R41, R42

\section{Introduction}

Chemical industry is one of the most developed branches of industry in Europe. It has long traditions in the industrial culture of occidental world. Developed over decades, it uses the newest technologies and lately, advanced IT solutions, which revolutionise both the international and intercontinental trade exchange. Despite that, throughout the last years, the structure of worldwide production has changed significantly. The goal of this article is to present these changes and predict the growth of the market in the future.

Based on the European Chemical Industry Council's ("CEFIC") report sales of chemicals in the European Union in 2017 had a total value of EUR 542 billion (Facts and figures 2018, The European chemical industry in a worldwide perspective). In the whole Europe that value was equal to EUR 654 billion. Worldwide, 
chemicals worth 3.5 EUR trillion have been produced, mostly by Asian producers (57.3\%). In comparison with 2016 the sales of chemicals increase by $4.6 \%$ (Figure 1).

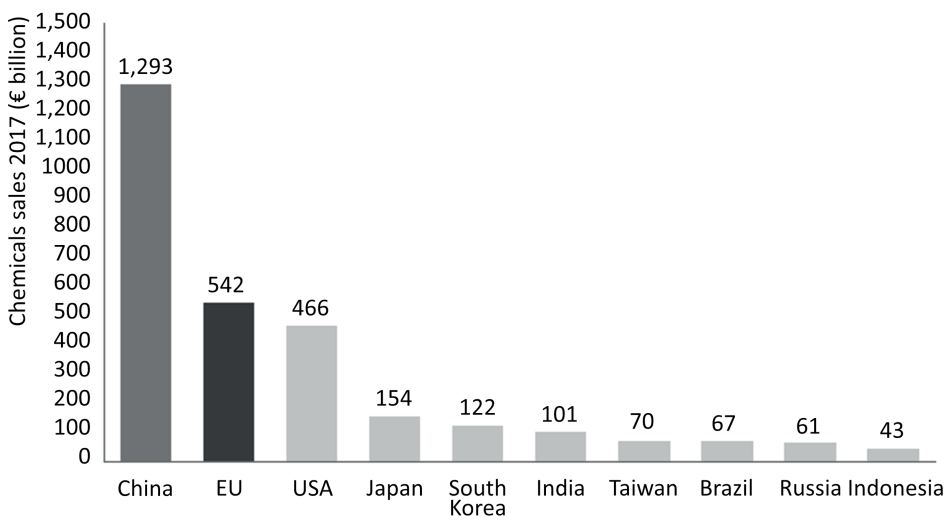

Figure 1. Largest chemical producers in the world in 2017 (billion EUR) Source: (CEFIC, 2018)

In the last years a significant change in the structure of the world leaders of chemical industry has occurred. European Union, NAFTA (USA, Canada, Mexico) and Japan have lost a share of the market, as they were replaced by China, which increased its share of the worldwide market from $14.8 \%$ to $37.2 \%$ since 2007 to 2017 (Figure 2).

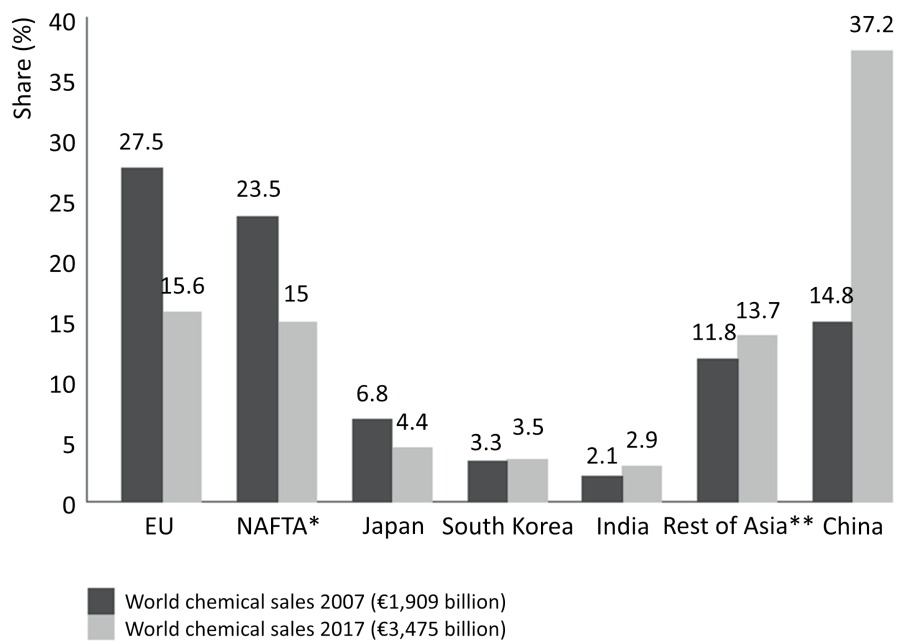

Figure 2. Structure of the market share of chemical producers in the world in 2007 and 2017 (\%) Source: (CEFIC, 2018) 
Interestingly enough, the value of the production sold by European producers hasn't been increasing since the economic crisis of 2008-2009, while their share of the market declines significantly. This proves the change of the worldwide structure, resulting from the intensive increases of production in the other parts of the world, mostly Asia. Interestingly, the share of the EU Member States in the worldwide production has decreased by $50 \%$ in the last 20 years (Figure 3).

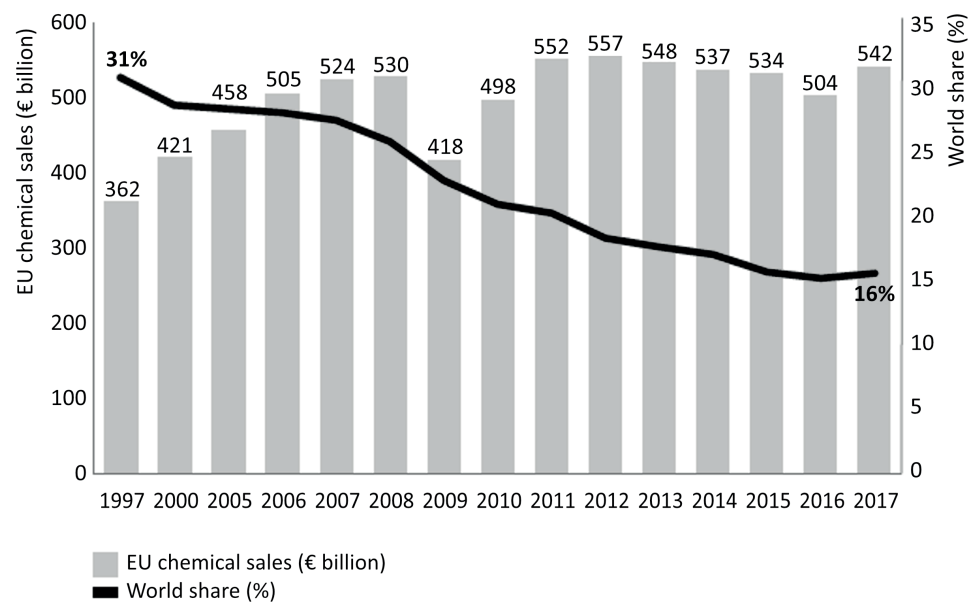

Figure 3. EU chemical sales (1997-2017)

Source: (CEFIC, 2018)

For many years now, the structure of the sales in the chemical industry of the European Union has been changing geographically. The domestic markets of the Member States have been losing their significance. The chemical sales on the domestic markets decreased from $34.0 \%$ in 2007 to $15,0 \%$ in 2017. This is due to the increasing intra-EU trade, which increased from $46 \%$ in 2007 to $56 \%$ in 2017. The sales of the chemical industry across the European border increased from $20 \%$ in 2007 to $29 \%$ in 2017 (Figure 4). 


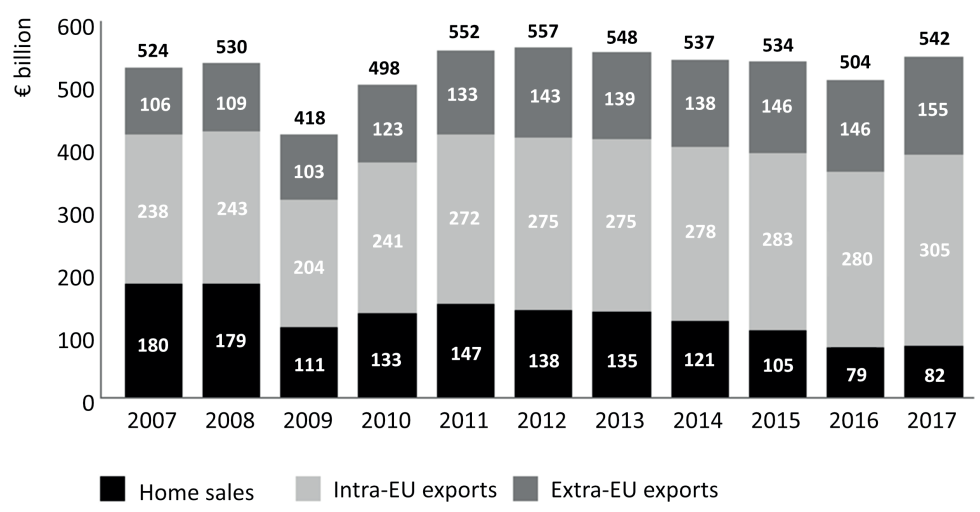

Figure 4. The geographical structure of the European Union chemical industry (billion EUR) Source: (CEFIC, 2018)

\section{The distribution channels of the chemical products and the transport modes used}

The modes of transport used in the distribution of the chemical products varies depending on the type of sales: intra-EU and extra-EU. The main modes of transport which are engaged in these logistic processes are:

1. for intra-EU sales:

- road transport,

- rail transport,

- intermodal transport;

2. for extra-EU sales:

- maritime transport,

- intermodal transport.

The road transport in the European Union has been increasing for five years in a row. Cabotage transport and international transport have been increasing along with it.

The total volume of all the cargo transported increased by $4.5 \%$ of the total tonne-kilometer from 2016 to 2017. In 2017 the overall value of the 5 year growth was $11.8 \%$, since 2013 .

The domestic transport in the EU, which is worth $63.5 \%$ of the total transport value increased by $9.9 \%$ in the years $2013-2017$, while the international and cabotage transport, which constitutes the $12.1 \%$ of the total transport value increased by a significant value of $38.5 \%$.

Poland is the leader when it comes to the total volume of cargo transported on road as it has an $18 \%$ share of the total road transport market in the EU (Figure 5). 


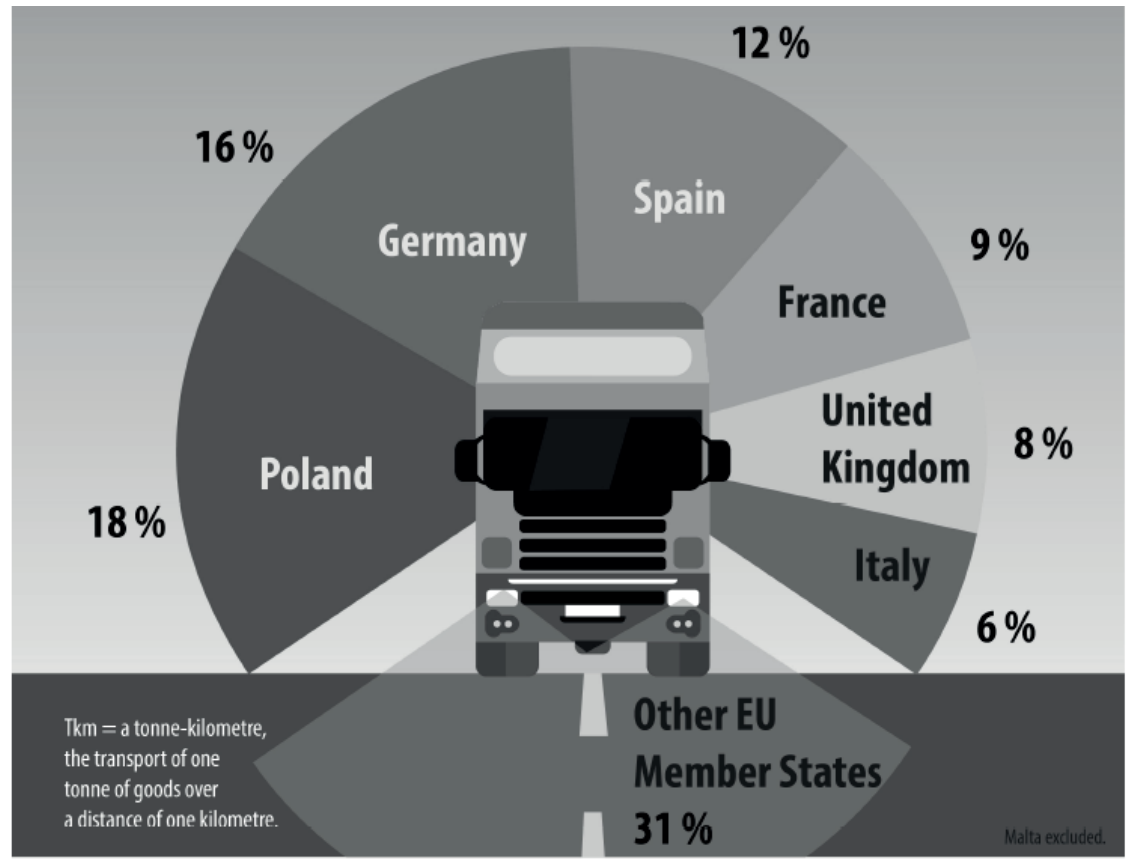

ec.europa.eu/eurostat

Figure 5. The leaders of the road transport market (\% of EU total $\mathrm{tkm}, 2017$ ) Source:(Road freight transport statistics, Eurostat 2018)

Poland increases its share of the market dynamically despite already being the leader. However, it's no longer the most rapidly increasing country in terms of share, which is understandable, given the current engagement of the Polish operators in the European road transport (Figure 6).

Liquid chemicals materials transportation has a share of $4.1 \%$ of the total volume transport and $6.9 \%$ of the total tonne-kilometer. This means that the liquid chemical products are transported at larger distances than the average distance in road transport. This is the result of the sales policy of large producers who construct their sales market based on the international customers. This means that the sales of chemical are mostly international which proves that the sector is at a high development level, which allows it to cross national and cultural barriers much faster than it happens for other sectors.

In comparison with the other sectors of the road transport, the transport of liquid materials was much more dynamical. In the years 2013-2017 the total volume increased by $10.5 \%$ and $8.6 \%$ of tonne-kilometer as presented by the next two figures (Figures 7,8). 


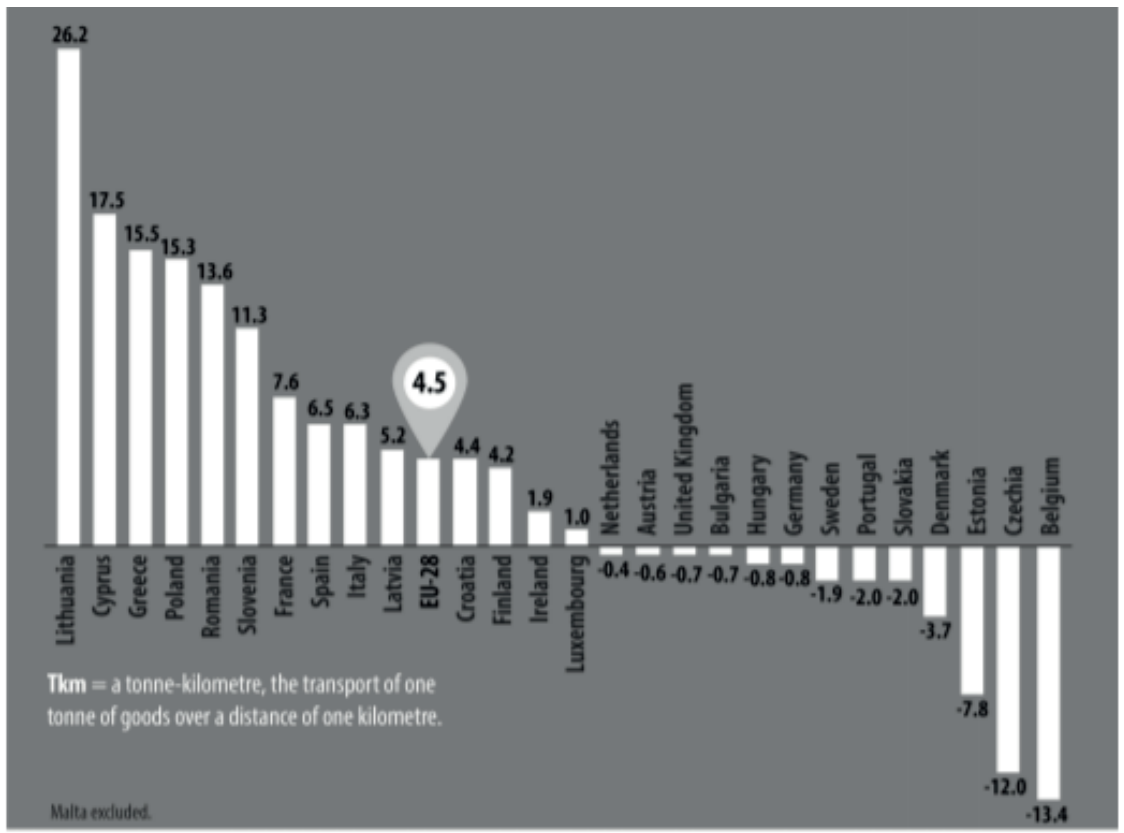

ec.europa.eu/eurostatio

Figure 6. Road freight transport - changes of the share of the market Source: (Road freight transport statistics, Eurostat 2018)

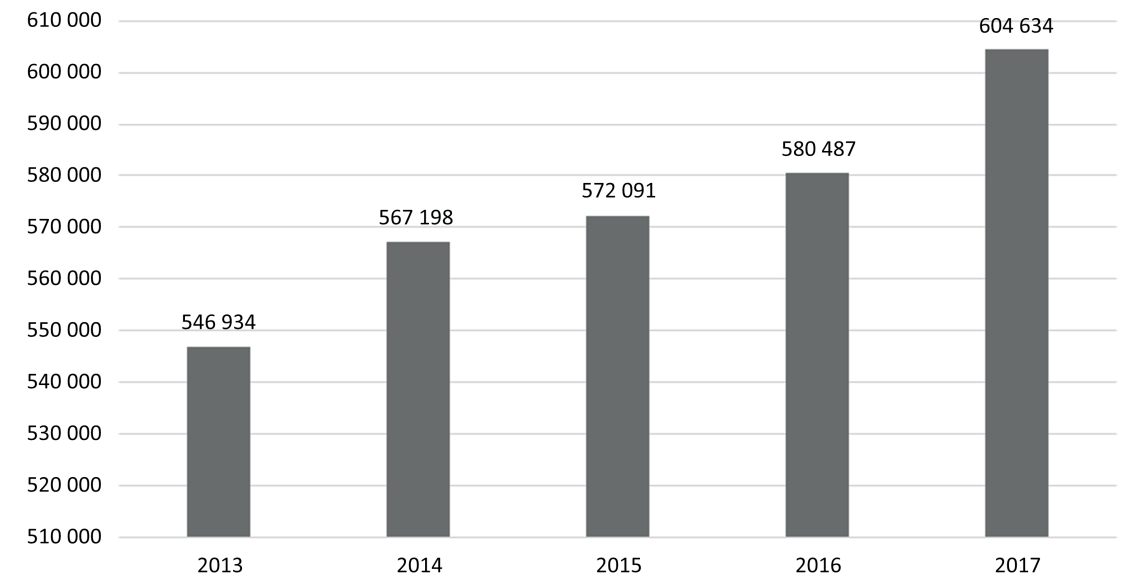

Figure 7. Road transport of chemical goods (1000 tonnes) Source: (Road freight transport statistics, Eurostat 2018) 


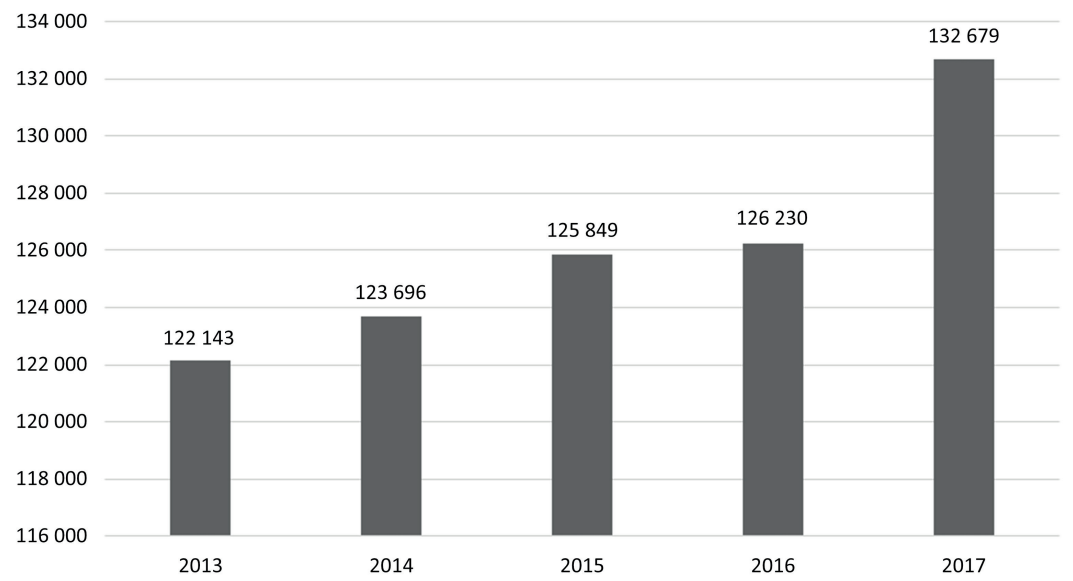

Figure 8. Road transport of chemical goods (million of tonne-kilometer)

Source: (Road freight transport statistics, Eurostat 2018)

The share of road transport of chemical products is nearly $50 \%$ of the total products transported. The cargo consists both of the products produced in the European plants as well as the goods transported for the trade companies which are a part of the global chemical logistics.

The rail and intermodal transport of the chemical cargo within the EU constitutes the remaining $50 \%$ of these products' logistics. They coexist very closely as they both use railway transport. However, tankers are loaded and unloaded directly between the chemical producer and the final customer, mostly large companies, using large volumes of product. The intermodal transport is much more open to smaller companies, to whom a single container with chemical cargo might be delivered using trucks, similarly to what happens with traditional cargo containers used for the transport of mass goods. The products can then be delivered to smaller customers, who have a smaller demand for goods and who don't have their own railway sidings. This is why medium production companies are also part of this sector. The main Rail Freight Corridors used for railway and intermodal transport in the EU are presented on the map (Figure 9).

The raw materials trade involves a mechanism of constant market negotiations between the largest producers and their direct competitors which include different sized companies as well as the trade companies which are a significant part of the market. This means that there is always a demand for different types of transportation at the market which supplement each other in terms of volume, speed, elasticity of the delivery and the ability to fulfill the demand for 'just in time' deliveries, which is focused on the maximal reduction of security stocks in order to minimize the costs of inventory of the producers. This is enhanced by the pressure from the strong industry which puts forward new challenges for the logistic services which need to adapt even better to the demand of the key market entities. 


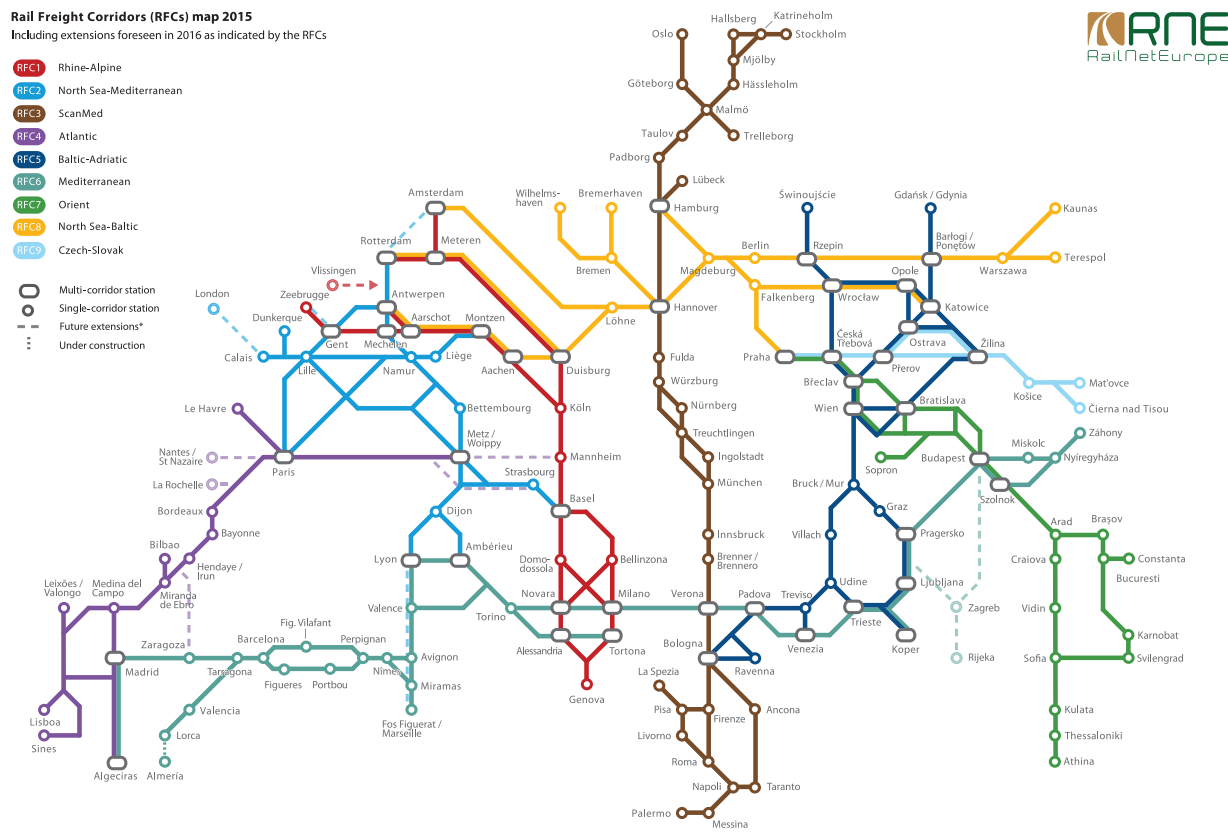

Figure 9. The map of the Rail Freight Corridors

Source: (European Road-Rail Combined Transport 2014-15 - UIRR Report 2015)

International maritime transport plays a key role in the mass transportation of goods for many years. The value of cargo transported over sea grows steadily for almost half a century with an exception of the years 2009-2010. Within the last 10 years the total volume of cargo transported overseas has increased by $33 \%$.

The transport of liquid chemical materials is carried out by chemical tankers. They are a specialist type of sea vessels, which have specialised cargo tanks which allow the transportation of liquids, including ADR (dangerous cargo). These constructions use specialised loading-unloading installations and the cargo handling is performed with the systems of pipelines and pumps which makes them different from traditional tankers. The installations are necessary to guarantee an efficient process on loading while providing the safety of the crew and the natural environment. Due to a high level of automatization these vessels are much more expensive than standard issue ships (Figure 10).

The transportation of chemical products also grows steadily, along with the market as a whole. Over the last 10 years, the volume of transport increased by $29 \%$, increasing by $5 \%$ in the years 2017-2018 (Figure 11).

Globally, the volume of intermodal transportation of chemical liquid materials (in tank containers) has been increasing significantly as proven by a record production of tank containers and a significantly increasing fleet of many logistic operators and leasing companies which specialize in the lease of tank containers (Figure 12). 


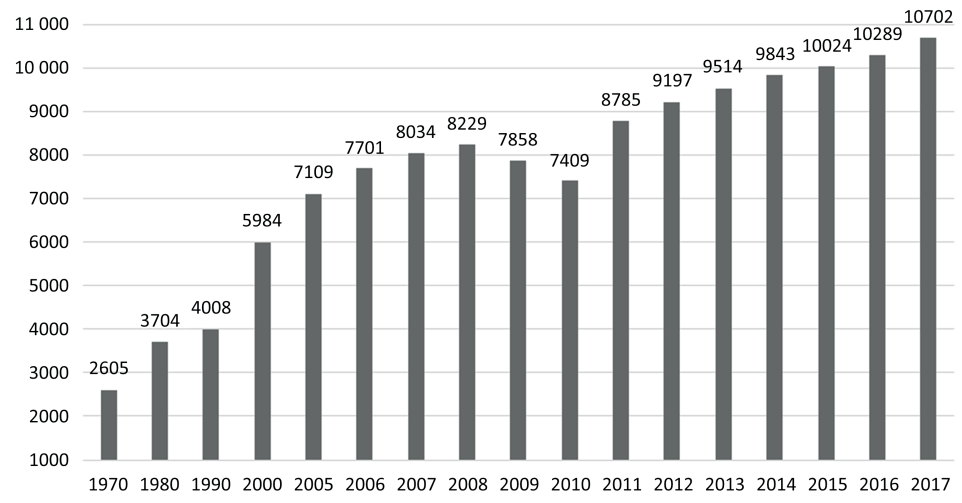

Figure 10. The volume cargo transported overseas (million tonnes) Source: (UNCTAD, Review of Maritime Transport 2018)

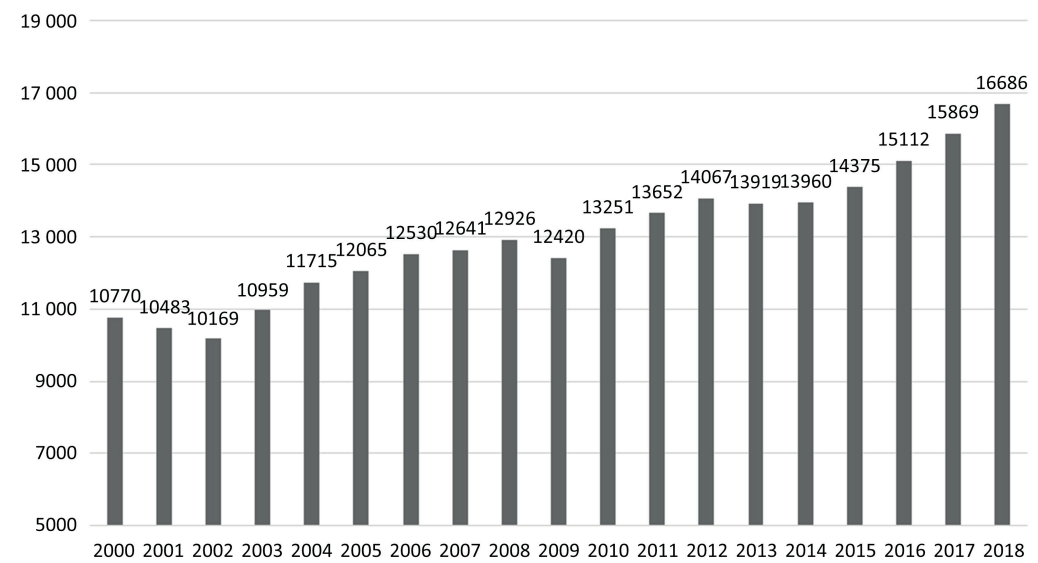

Figure 11. The volume of chemical products transported overseas (million tonnes) Source: (UNCTAD, Review of Maritime Transport 2018)

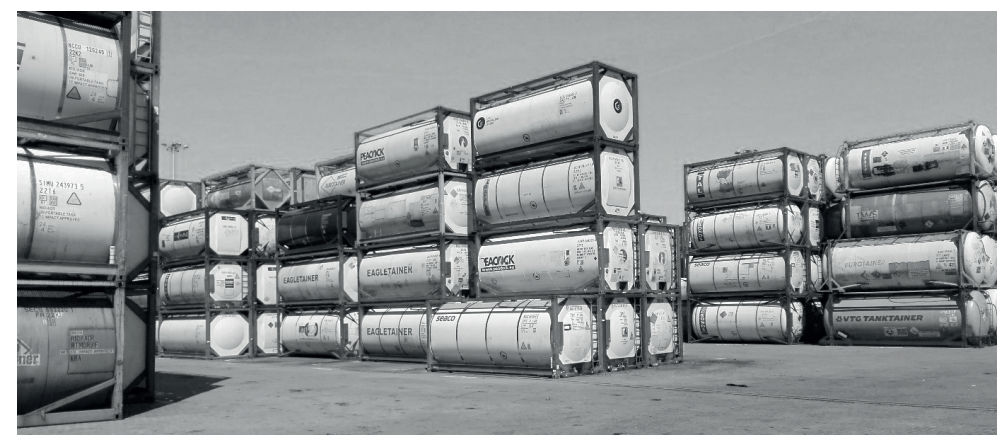

Figure 12. A fleet of tank containers

Source: (Trans Polonia Group press materials) 
There are many reasons for this growth. It has now become a trend that much of the cargo which was previously transported in specialised barrels or tanks are now transported in tank containers. Their use has also been increased in the domestic transport of liquid materials in China. This increased the demand for new tank containers and their lease (Figure 13).

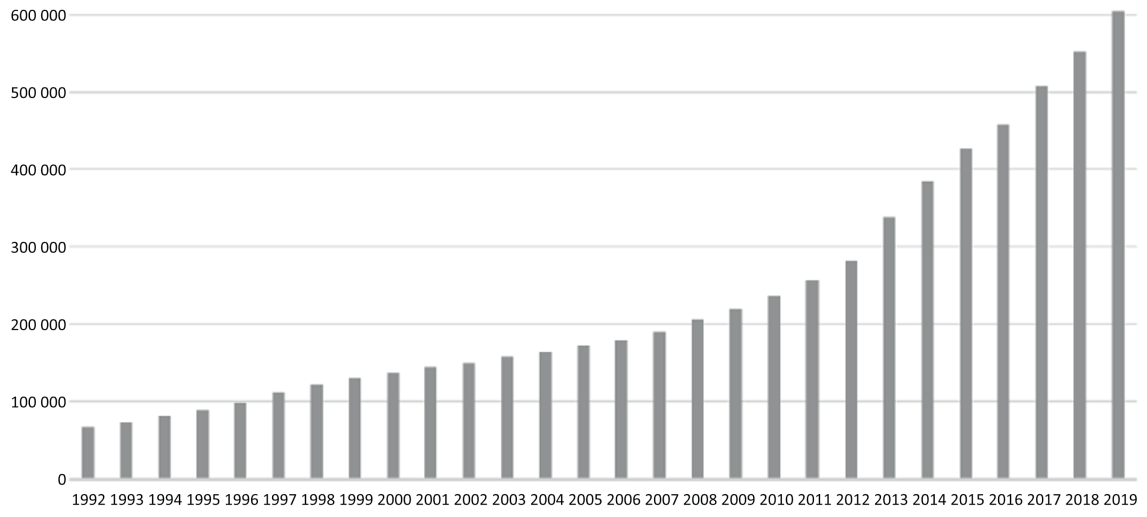

Figure 13. The global fleet of tank containers Source: (ITCO, Global Tank Container Survey 2019)

According to the ITCO Global Tank Container Survey in 2019, the global fleet of tank containers increased by almost $11 \%$ in 2018 in comparison to 2017. This research indicates that at the beginning of 2019 there were 604,700 units across the world in comparison to 552,000 tonnes the year before. This means that there has been a yearly growth of $10.81 \%$, larger than $8.66 \%$ the year before. The number of containers produced also increased. 59,700 containers were produced in 2018 while only 48,500 were produced in 2017 , which indicates a $23 \%$ yearly increase.

\section{Growth perspectives of Logistics solutions based on the market demand, the natural environment and the technical options}

In the era of ecological challenges in front of every branch of industry, the ecological demands are the first and foremost when planning the growth potential. The $\mathrm{CO}_{2}$ emission norms are more rigorous every year. They are used to assess the effect which different modes of transport have on the natural environment and to predict the potential future trends (Figure 14).

The maritime transport and the pipeline transport are fairly green, followed by the railway transport, the barge transport and the road transport. The road transport and the pipeline transport have the highest volume share, while the road transport and the maritime transport have the highest shares of the $\mathrm{CO}_{2}$ emissions. The volume switch to more ecological modes of transport might increase the delivery times and disturb the logistic supply chain of the chemical industry. 
In order to decrease the global $\mathrm{CO}_{2}$ emissions a combination of coordinated activities is needed, including legal, technological and organisational changes. At the same time, a taxation of the emissions and reference to the market indicators will affect the structure of the transport costs.

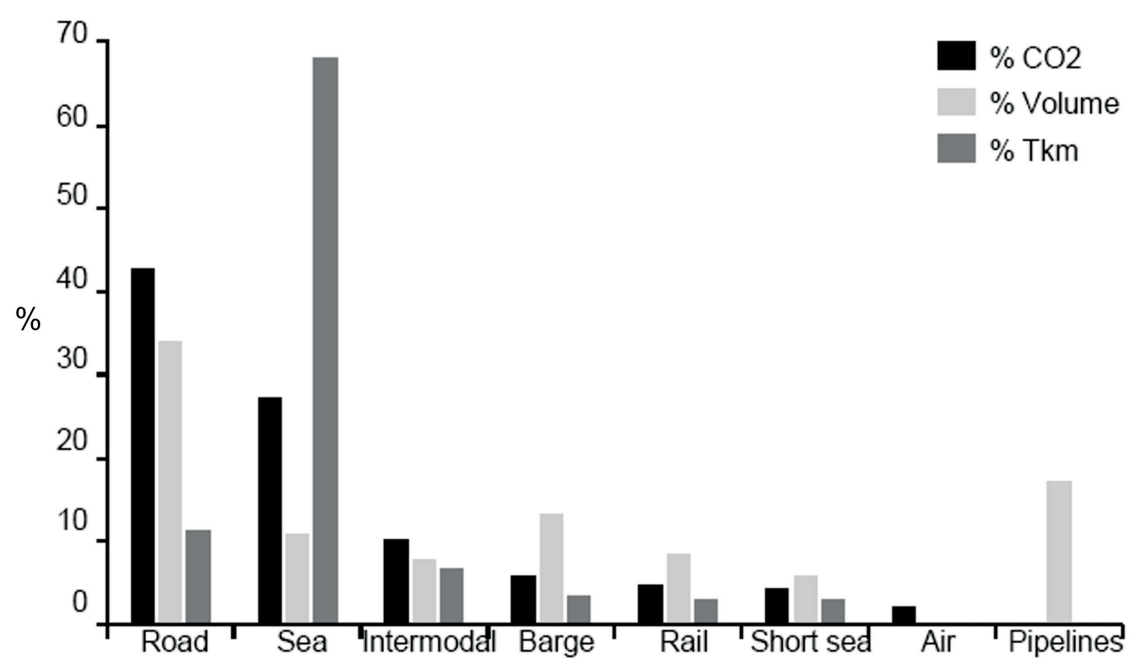

\begin{tabular}{|l|c|}
\hline Transport mode & $\mathrm{gCO}_{2} /$ Tonne-km \\
\hline Air & 602 \\
\hline Road transport & 62 \\
\hline Intermodal road / barge & 34 \\
\hline Barge transport & 31 \\
\hline Intermodal road / rail & 26 \\
\hline Rail transport & 22 \\
\hline Intermodal road / short sea & 21 \\
\hline Short sea & 16 \\
\hline Deep-sea container & 8 \\
\hline Deep-sea tanker & 5 \\
\hline Pipelines & 5 \\
\hline
\end{tabular}

Figure 14. Share of different transport modes in chemical logistics (estimate based on Cefic survey with input from 12 major chemical companies)

Source: (CEFIC, Delloite, Chemical Logistics Vision 2020)

The economy as a whole increases in the European Union and so does the chemical industry. This means that there is a higher demand for the logistic handling of these processes. The current structure of the transportation volume indicates that the road transport is able to handle them the most efficiently. Nearly $35 \%$ of all the chemical cargo is transported on the roads due to the elasticity, mostly 
desired by smaller companies. The market expectations of the companies affect the demand for a given transport mode. The most important factors are the ability to transport goods fast and to react dynamically to the changes of the production and sales processes.

It's worth noting that the ability to increase the volume of transport will be affected by the capacity of the road transport network in the EU. Right now, it's already a significant problem which is bound to increase in the future. On the other hand, the European Commission supports the intermodal transport, which has a lower negative environmental impact and a relatively higher transport safety. On the other hand, it has its problems, mostly: delays, reduced elasticity, large costs of rail infrastructure access, uneven coverage of the EU with rail infrastructure and a small amount of cross-docking terminals.

The intercontinental maritime transport faces the necessity to significantly reduce the $\mathrm{CO}_{2}$ emissions, due to the more rigorous environmental norms. All across the world this will lead to an increased level of the costs and a reduced competitiveness. However, in the foreseeable future, this mode of transport will at least hold its relevance due to a lack of potential alternatives.

There are a lot of new technical solutions introduced in transport at the very moment including the change from heavy duty oils to LPG and the change of the drives from the common direct combustion engines to indirect drives using internal power-plants producing energy for electric motors. It can be assumed that most of the changes will be aimed at reducing the $\mathrm{CO}_{2}$ emissions and the negative environmental impact which should increase the pressure on the engine producers so that they introduce new, more efficient technologies.

In conclusion, based on the current structure of the transportation of liquid chemical materials and the changes occurring at the moment within the whole transport sector, it can be said that within the next 10 years the changes will be more evolutionary than revolutionary. Current trends will continue to exist within the different transport modes. However, they may be potentially disturbed in the future due to the visible tensions between the main chemical producers (China, EU, USA), which could potentially lead to a trade war.

\section{References}

CEFIC (2018), Facts $\mathcal{E}$ Figures. Available from https://cefic.org/app/uploads/2018/12/ Cefic_FactsAnd_Figures_2018_Industrial_BROCHURE_TRADE.pdf.

CEFIC, Delloite (2011), Chemical Logistics Vision 2020. The next decade's key trends, impacts and solution areas. Available from https://cefic.org/app/uploads/2018/12/Chemical-Logistics-Vision-2020-190911_REPORT_TRANSPORT_AND_LOGISTICS.pdf.

Eurostat. Statistics Explained (2018), Road freight transport statistics. Available from https:// ec.europa.eu/eurostat/statistics-explained/index.php/Road_freight_transport_statistics.

International Tank Container Organisation (ITCO) (2019), Global Tank Container Survey 2019. Available from https://www.international-tank-container.org/storage/uploads/ ITCO_2019_Global_Tank_Container_Fleet_Survey_Final.pdf.

Trans Polonia Group (2019), press materials. Available from http://transpolonia.pl/.

UIRR Report (2015), European Road-Rail Combined Transport 2014-15. Available from http:// www.uirr.com/en/component/downloads/downloads/1102.html. 
United Nations Conference on Trade And Development (UNCTAD) (2018), Review of Maritime Transport 2018. Available from https://unctad.org/en/PublicationsLibrary/rmt2018_en.pdf.

\section{Corresponding author}

Dariusz Cegielski can be contacted at: dc.transpolonia@gmail.com 